\title{
Racionalidad técnica y excepción. La crítica de Giorgio Agamben a la doctrina del estado de excepción de Carl Schmitt y sus alcances ${ }^{1}$
}

\section{Technical Rationality and exception. Giorgio Agamben's critique of Carl Schmitt's doctrine of the state of exception and its scope}

\author{
Hugo Eduardo HERRERA \\ Universidad Diego Portales (Chile)
}

Recibido: 13-07-2013

Aceptado: 28-10-2013

\section{Resumen}

Giorgio Agamben plantea que mediante el estado de excepción se logra vincular, por medio de la violencia, dos dimensiones carentes en principio de vínculo entre sí: nuda vida y normatividad. El estado de excepción parece encarnar así una racionalidad manipuladora. En contraste, en el pensamiento de Schmitt hay una permanente preocupación por el problema de la técnica, a la cual devela como racionalidad manipuladora. En este artículo se intenta determinar los alcances y límites de la teoría del estado de excepción de Schmitt, a partir de un análisis de su comprensión de la racionalidad técnica.

Palabras clave: Estado de excepción, racionalidad técnica, excepción, orden jurídico, nuda vida.

\begin{abstract}
Giorgio Agamben indicates that through the state of exception it is possible to connect two dimensions which, in principle, are lacking of any relationship between them, namely bare life and normativity. The state of exception seems to express a manipulative rationality by which life is subject to violence. In contrast, Schmitt addresses the problem of technology and reveals that it, ultimately, is a form of manipulative rationality. Through an
\end{abstract}

\footnotetext{
1 Este artículo forma parte del proyecto de investigación FONDECYT Nr. 1110012.
} 
analysis of his understanding of technical rationality, this article attempts to determine the scope and limits of the Schmittian theory of the state of exception.

Keywords: State of exception, technological rationality, exception, juristic order, bare life.

Desde temprano y hasta la última de sus obras, Carl Schmitt se ocupó del problema de la racionalidad técnica. Su tratamiento de la cuestión tiene un talante crítico. De un lado, entiende que ella es una forma limitada de racionalidad, que prescinde de aspectos constitutivos de la existencia humana, aspectos que, sin embargo, ella misma, como forma de comprensión, supone. De otro lado, Schmitt muestra que se trata de una forma de racionalidad que, admitida sin fronteras, genera consecuencias negativas para el ser humano. Ella termina, a su juicio, vulnerando lo que entiende como las condiciones de una "existencia humana razonable". 2

En los últimos años, Giorgio Agamben ha abordado con detalle la teoría schmittiana del estado de excepción. Agamben muestra que el estado de excepción termina funcionando como un dispositivo técnico de control ilimitado de los sometidos a él. El estado de excepción estaría inescindiblemente atado a una lógica de la manipulación del individuo. Esta consideración evidencia una tensión o incluso una contradicción en el pensamiento de Schmitt: por una parte, él critica a la racionalidad técnica como una racionalidad manipuladora, que trata como objeto al sujeto; por otra, empero, asume una doctrina del estado de excepción que, precisamente, trata como objeto al sujeto.

En este trabajo intentaré mostrar la tensión que existe entre la doctrina del estado de excepción y la crítica schmittiana de la racionalidad técnica, así como inquirir en si hay o no un modo de admitir esa doctrina dentro del sistema de pensamiento de Schmitt. Para tal efecto, tomaré como punto de partida la mencionada crítica de Agamben al estado de excepción, en la cual éste aparece con especial claridad como un dispositivo técnico-jurídico de manipulación. La determinación acabada del modo en el cual esa doctrina del estado de excepción se inserta en el pensamiento de Schmitt requeriría emprender un estudio general de su obra, que no puedo realizar aquí. En cambio, me concentraré en la crítica schmittiana de la racionalidad técnica, de la cual emerge lo que puede entenderse como una concepción jurídica de la existencia. En esa concepción, la existencia surge como una unidad previa a las separaciones entre hecho y norma en virtud de la cual es posible establecer límites a una doctrina del estado de excepción. La crítica de Schmitt a la racionalidad técnica descansa, además, en un segundo aspecto de su pensamiento, que tiene alcances generales para su obra, a saber, su teoría de la excepción, en la cual dicha excepción aparece como trascendente a toda regla y normalidad, así como a los dispositivos técnicos con los cuales se la pretende controlar. A partir de aquella crítica y de estas ideas, entiendo que es posible limitar los alcances que Agamben le otorga a la doctrina del estado de excepción de Schmitt y alcanzar una comprensión del derecho que se distancia de la racionalidad técnica de la manipulación.

2 La expresión proviene del texto "Die Lage der europäischen Rechtswissenschaft". Verfassungsrechtliche Aufsätze aus den Jahren 1924-1954. Materialien zu einer Verfassungslehre. Berlín: Duncker \& Humblot, 2003, 423. 


\section{Schmitt, entre el derecho y la técnica}

En diversos textos Schmitt se autocomprende como jurista y en esta autocomprensión pretende distinguirse del racionalismo de la técnica. ${ }^{3} \mathrm{El}$ derecho se ubica, a su juicio, entre el substancialismo de la teología y el funcionalismo de la técnica. ${ }^{4}$ Desde temprano, además,se ocupó en comprender la racionalidad técnica y descubrir su carácter de racionalidad manipuladora o del control. La racionalidad técnica, entiende Schmitt, intensifica las relaciones de poder. La ciencia y la técnica modernas incrementan la predictibilidad y el control de los procesos naturales, de tal suerte que con ellas los poderosos cuentan con mecanismos más eficaces de dominio. En "Die Einheit der Welt" escribe Schmitt: "El ser humano, biológicamente y por naturaleza un ser absolutamente débil y menesteroso, se procura, mediante la técnica, un nuevo mundo, en el cuál él es el ser más fuerte, incluso el único".5 Schmitt repara en la idea de que el ser humano es también un ser natural. En consecuencia, el incremento del dominio sobre la naturaleza, que se logra mediante la técnica, significa también un incremento del dominio técnico del hombre sobre el hombre. 6

Schmitt advierte respecto a que, una vez que el control incrementado se impone, "[1]a peligrosa pregunta de en cuáles hombres se concentra el poder inmenso sobre otros hombres, y que se halla conectada necesariamente con aquel incremento de los medios técnicos, no puede ser formulada". ${ }^{7}$ Vale decir, no es sólo que el ser humano quede subyugado a un sistema racional de control. El incremento del control técnico de unos hombres sobre otros llega además a un punto extremo, en el cual los detentadores del poder buscan asegurar su invisibilidad y, por tanto, terminan restando sus acciones poderosas al escrutinio público, precisamente mediante sus mecanismos de poder.

A diferencia de la racionalidad técnica, la racionalidad jurídica no conduciría a esas consecuencias. Esta se aleja de la manipulación banalizadora. La racionalidad jurídica lograría comprender diferenciadamente al ser humano en su carácter específico, fundamentalmente distinto a los entes mundanos. Allí el ser humano aparece como instanciación de un sujeto que, en tanto opera comprensivamente, es irreductible al carácter de un objeto disponible. ${ }^{8}$ O también: como persona que, en cuanto portador de fines, resulta irreductible a la condición de cosa natural o mero medio. ${ }^{9} \mathrm{O}$ también: como alguien que, en tanto es siempre

3 Cf. C. Schmitt. Der Nomos der Erde im Völkerrecht des Jus Publicum Europaeum. Berlín: Duncker \& Humblot, 1997, 6; Glossarium. Berlín: Duncker \& Humblot, 1991, 17, 23, 132, 219, 310, 311; Ex Captivitate Salus. Berlín: Duncker \& Humblot, 2002, 89.

4 Cf. C. Schmitt. Glossarium, 311; Der Nomos der Erde, 6.

5 C. Schmitt. "Die Einheit der Welt". Merkur 47 (1952), 9.

${ }^{6}$ Cf. C. Schmitt. Glossarium, 10, 53, 82. El ser humano va quedando inmerso así en un sistema social crecientemente racionalizado. Respecto de la producción, Schmitt nota que, a diferencia de la "herramienta", que es poseída y utilizada por el trabajador, la "máquina" de la moderna técnica "trasciende en ella misma al ser humano que posee la herramienta, al obrero". C. Schmitt. Op. cit., 84-85. En el contraste entre herramienta y máquina, la primera aparece como estando al servicio del trabajador, mientras que con la máquina se instaura un modo de actividad en el cual el trabajador es insertado, que lo sobrepasa en la medida en que lo funcionaliza.

7 C. Schmitt. "Die Einheit der Welt", 9.

8 Cf. C. Schmitt. Glossarium, 82-84.

9 Cf. C. Schmitt, Politische Theologie. Berlín: Duncker \& Humblot, 1996, 40; Glossarium, 10; "Die Einheit der Welt", 9-10. 
"indeterminable, insondable" y "pregunta abierta" es inabordable al modo en que determino cosas. ${ }^{10} \mathrm{~A}$ diferencia de la racionalidad técnica, que tiene un "interés objetivo, impersonal", 11 que la hace incapaz de distinguir entre ser humano y cosa, la atención al carácter personal de lo humano lo vuelve apto para efectuar esa distinción. Ambas, cosas y personas, pueden ser controladas. Tanto con cosas como con personas se puede calcular y establecer relaciones generales. Por eso, cuando la comprensión técnica de dominio y cálculo se impone en la vida jurídica, el "derecho" se vuelve "poder".12

Esta distinción entre racionalidad jurídica y técnica se vería, sin embargo, amenazada o contrariada por la teoría schmittiana del estado de excepción. Si es verdad que ella ocupa un lugar central en el pensamiento jurídico de Schmitt, entonces en el núcleo de su comprensión del derecho estaría emplazada una doctrina en la cual se justifica jurídicamente la manipulación y el control violento de la existencia humana.

\section{El estado de excepción como dispositivo técnico}

La doctrina del estado de excepción ocupa un lugar significativo en el pensamiento schmittiano. En cierto modo, podría decirse que en Teología política Schmitt comprende al derecho desde la excepción jurídica. Giorgio Agamben muestra que la doctrina schmittiana del estado de excepción evidencia una racionalidad manipuladora o del control. Esta tesis, de ser cierta, haría evidente una tensión o incluso una contradicción en el pensamiento de la excepción en Schmitt: El mismo Schmitt, que tanto empeño pone en sacar a la luz diferenciadamente las insuficiencias y los riesgos de la racionalidad técnica, termina sucumbiendo ante aquélla en su teoría del estado de excepción.

En esa doctrina, como muestra Agamben, se trata de validar un dispositivo técnico destinado a suspender jurídicamente el derecho de la normalidad, vale decir, aquel que, según Schmitt, relativiza las pretensiones de las partes y resguarda la autonomía individual, la subjetividad del sujeto, su carácter de persona, para pasar a otorgarle prerrogativas absolutas al soberano, incluida la de tratar como mero objeto al sujeto, como cosa a la persona.

Agamben repara en un uso creciente que se ha hecho del estado de excepción desde la Primera Guerra Mundial. En vez de declararse dicho estado ante una crisis ya producida, se lo ha empleado desde entonces de manera autónoma, para producir soberanamente, mediante su declaración, la situación excepcional. ${ }^{13}$ Vale decir, se lo emplea no sólo como un mecanismo de reacción ante la situación política extrema ya acontecida, sino que se le da un uso activo, para declarar y así producir esa situación extrema. En cierto modo, se puede afirmar, usando palabras de Schmitt -que contrapone la racionalidad jurídica a la racionalidad técnica, precisamente en la medida en que la primera se hace cargo del estatus especial del ser

10 C. Schmitt, Der Begriff des Politischen. Berlín: Duncker \& Humblot, 1996, 60.

11 C. Schmitt. Politische Theologie, 40.

12 C. Schmitt. Theodor Däublers "Nordlicht”. Berlín: Duncker \& Humblot, 1991, 61; cf. Glossarium, 53.

13 Cf. G. Agamben. Homo sacer. Valencia: Pre-textos, 1998, 22, 74; Estado de excepción. Valencia: Pre-textos, 2011, 125-127. 
humano y que, debido a este reconocimiento, no es puramente activa14-, que se ha pasado desde una concepción jurídica del estado de excepción, a una comprensión preponderantemente técnica, activa, manipuladora de esa institución. En esta nueva situación puede afirmarse que la excepción, como estado de excepción, se ha vuelto normalmente aplicable.15 "Hoy" -señala Agamben- "en un momento en que las grandes estructuras estatales han entrado en un proceso de disolución", "la excepción [...] se ha convertido en regla".16 El uso activo que se hace del estado de excepción, denunciado por Agamben, responde a lo que Schmitt llama el "funcionalismo total" de la técnica. ${ }^{17}$

Este nuevo uso experimentado por el estado de excepción en el paso de una noción reactiva a una activa o espontánea del mismo, no es, para Agamben, simplemente un abuso de esta figura, una etapa transitoria desde la que se pueda dar marcha atrás y recomponer, por ejemplo, lo que con Schmitt podríamos llamar un uso jurídico y no meramente técnico del estado de excepción. Si así fuera, la tensión entre la crítica schmittiana de la racionalidad técnica y su doctrina del estado de excepción admitiría una solución, que consistiría en retrotraer las cosas a la situación en la que se hallaban antes del empleo activo del dispositivo. Este uso activo es una posibilidad extrema de activación del estado de excepción, pero Agamben entiende que el estado de excepción es, ya en sí mismo, originariamente un aparato técnico ficticio, una "ficción". ${ }^{18}$ Como tal, es condición de la posibilidad de toda conformación jurídica o normativa de la vida humana. ${ }^{19}$

El estado de excepción cumple la función de vincular "violencia y derecho", "la vida y la norma", entre los cuales "no hay ninguna articulación substancial."20 El estado de excepción es puro funcionalismo sin substancia, sin referencia a una realidad distinta a esa construcción racional. No viene ya a recomponer un orden, sino simplemente a establecer un vínculo ficticio entre norma y vida, un vínculo amparado en la violencia.

En la caracterización del estado de excepción planteada por Agamben emerge una cierta ambigüedad. De un lado, el estado de excepción empieza, en un momento determinado de la historia (luego de la Primera Guerra Mundial), 21 a ser usado activamente para producir la excepción. Este comienzo histórico de un uso activo, importa que antes de dicho comienzo el uso era reactivo: se esperaba que tuviera lugar la excepción para declarar el estado de excepción. Sin embargo, de otro lado, sostiene Agamben que el estado de excepción en sí mismo, vale decir, siempre (o sea: antes y después del momento en el que comenzara a ser declarado activamente para producir la excepción), ha sido una institución de carácter ficticio, en el sentido que viene a establecer un vínculo entre lo que no está articu-

\footnotetext{
14 Cf. C. Schmitt. Glossarium, 10, 82-84; Politische Theologie, 40; "Die Einheit der Welt", 9-10; Der Begriff des Politischen, 60.

15 Cf. Jef Huysmans. "The Jargon of Exception. On Schmitt, Agamben and the Absence of Political Society”. International Political Sociology 2 (2008), 171-174.

16 G. Agamben. Homo sacer, 22; cf. 19.

17 C. Schmitt. Glossarium, 311.

18 G. Agamben. Estado de excepción, 125.

19 En este sentido, apunta Agamben que el estado de excepción y la relación que establece, es "originaria"; G. Agamben. Homo sacer, 142.

20 G. Agamben. Estado de excepción, 126.

21 G. Agamben. Op. cit., p. 24.
} 
lado "en sí", a saber, entre derecho y violencia, entre norma y vida. La vida es lo excepcional. El derecho, en cambio, supone la normalidad. ${ }^{22}$ Entre la vida, excepcional, y el derecho, es decir, entre la excepción y la racionalidad normalizadora, no existe relación intrínseca, sino que el derecho siempre viene simplemente a sobreponerse a la vida.

Pero, ¿cómo logra establecerse este vínculo ficticio entre norma y vida, derecho y violencia en el estado de excepción? El derecho es incapaz de hacerse cargo, en un primer momento, de la nuda vida, pues ella es en un comienzo inabarcable desde la racionalidad normativa. ${ }^{23} \mathrm{La}$ vida desnuda siempre amenaza romper la normalidad, salirse de ella, volverse excepcional. En apoyo de la racionalidad normativa viene, entonces, el estado de excepción, el cual opera como dispositivo capaz de comprender de algún modo a la vida desnuda y forzarla a someterse al derecho, en la medida en que se contempla a la excepción como un supuesto para la intervención del soberano. El soberano, dado el caso de anormalidad, puede suspender el derecho y someter así, por violencia, la vida desnuda. ${ }^{24}$ Esa acción de sometimiento soberano es comprendida por el propio derecho, suspendido en el acto de declaración del estado de excepción, como un caso de aplicación del derecho, es decir: es justificada jurídicamente, no más que de tal manera que el derecho se auto-anula como normatividad y límite. 25

En esta dinámica, el soberano pasa a ocupar, junto al estado de excepción, un lugar paradójico. Está fuera y dentro del derecho: "La situación creada por la excepción [...] no puede ser definida ni como una situación de hecho ni como una situación de derecho, sino que introduce entre ambas un paradójico umbral de indiferencia”. ${ }^{26}$ Está fuera, pues suspende el derecho vigente, para pasar simplemente a actuar soberanamente, esto es, mediante el ejercicio de la violencia estatal. Sin embargo, el soberano también está dentro del derecho, pues el estado de excepción es un dispositivo autorizado jurídicamente, de tal suerte que, como he señalado, la violencia que ejerce el soberano en virtud de ese estado de excepción, puede ser vista como caso de limpia aplicación del derecho.

El correlato de esa intervención soberana es el individuo carente de protección, considerado como vida desnuda, es decir, como sujeto pasivo de la violencia soberana, no sujeta ya a ningún límite jurídico. ${ }^{27}$ Análogamente al soberano, el individuo queda, de cierto modo, a la vez que incluido en el derecho, excluido de él. Es incluido, en tanto que el acto soberano de violencia que se ejerce sobre él (y de exclusión del derecho, según veremos), es un acto jurídicamente autorizado, gracias al estado de excepción. El individuo es, sin embargo, a la vez, excluido del derecho, pues el estado de excepción, según el cual la violencia soberana actúa, se realiza bajo suspensión del derecho.

En esta descripción de la relación originaria de poder, el estado de excepción aparece como el mecanismo que le permite al poder soberano y al derecho someter al individuo, de manera que su existencia cae, a la vez que bajo una racionalidad jurídica, en verdad, fundamentalmente, bajo una racionalidad soberana de mera disposición. Pues el estado de excep-

\footnotetext{
22 Cf. G. Agamben. Homo sacer, 32.

23 Cf. G. Agamben. Op. cit., 31-33.

24 Cf. G. Agamben. Op. cit., 42-44.

25 Cf. G. Agamben. Estado de excepción, 125-127.

26 G. Agamben. Homo Sacer, 31.

27 Cf. G. Agamben. Op. cit., 108-112.
} 
ción le permite al soberano producir jurídicamente la situación de excepción, en la cual el derecho es suspendido, y en la que el súbdito queda capturado, de tal suerte que puede disponerse de él sin límite. Más aún: el soberano está aquí facultado jurídicamente para realizar esa disposición, de modo que sus acciones violentas pueden ser vistas siempre como casos de aplicación del derecho. El estado de excepción como institución jurídica es así funcional al poder soberano, pues permite la vulneración del aspecto normativo del derecho, pero de una forma en la que esa vulneración puede aparecer revestida de derecho, en tanto que en el estado de excepción el soberano es dotado jurídicamente de plenos poderes para la aplicación del derecho. ${ }^{28}$

La descripción que Agamben hace del estado de excepción muestra que allí se realiza una manipulación del ser humano por un dispositivo técnico-jurídico. Esta descripción evidencia una tensión o incluso una contradicción en el pensamiento de Schmitt. Pues en la comprensión schmittiana del derecho, aparece jugando un papel fundamental en el núcleo mismo del derecho un dispositivo jurídico caracterizado claramente por Agamben como un mecanismo de manipulación de unos seres humanos sobre otros. Si se atiende a lo que dice Agamben, la teoría schmittiana del estado de excepción constriñe la vitalidad de la vida concreta, precisamente en tanto que, mediante el dispositivo soberano del estado de excepción, la incorpora al derecho (y la excluye de la normalidad del derecho) y a una lógica del poder soberano, que, en tanto que aplicación del derecho, es jurídico, y, como suspensión del derecho, es extrajurídico. El de Schmitt aparece así como un racionalismo funcionalista de segundo orden. A diferencia de un Hans Kelsen, por ejemplo, que se niega a extender el campo de la racionalidad jurídica allí donde impera la vida concreta de manera excepcional, Schmitt no duda en hacer intervenir al derecho, mediante un dispositivo capaz de ampliarlo más allá de la normalidad, aunque al costo de vincular necesariamente la normatividad (suspendida) y el poder soberano. El resultado, sin embargo, es parecido al del racionalismo normativista o al del racionalismo de la técnica, a saber, la incorporación de la vida concreta en un dispositivo heterónomo incapaz de hacerse cargo de su espontaneidad vital. La teoría del estado de excepción vendría a ser un intento de controlar la excepción política, mediante un dispositivo de carácter técnico, en el cual el ser humano resulta, en último término, manipulado.

\section{Excepción absoluta y relativa en Schmitt y función terapéutica de la excepción absoluta}

La necesidad de una interpretación de la doctrina del estado de excepción que atienda al lugar que ella ocupa en la totalidad de la obra de Schmitt, se evidencia en la observación que realiza John P. McCormick, respecto a la diferente atención que Schmitt presta a la excepción en La dictadura, del año 1921, texto en el cual Schmitt privilegia el estado de excepción dictatorial por sobre la excepción, la cual recibe una valoración negativa, y en Teología política, donde en cambio la excepción aparece como "peligrosa, pero valiosa, en la medida en que es una ocasión de revitalización de la existencia". ${ }^{29} \mathrm{Si}$ en estas obras tan cercanas, la

28 Cf. G. Agamben. Estado de excepción, 125-127.

29 J. P. McCormick. Carl Schmitt's Critique of Liberalism. Against Politics as Technology. Cambridge: Cambridge University Press, 1999, 136. 
excepción es valorada de diversa forma, cabe preguntarse por los alcances que la doctrina del estado de excepción y la comprensión de la excepción tiene en la obra de Schmitt. Lo que intentaré probar en los puntos que siguen, es que en el pensamiento de Schmitt hay elementos que permiten atenuar los alcances de la teoría del estado de excepción.

La racionalidad jurídica se distancia, para Schmitt, en último término, de la racionalidad técnica, porque aquélla alcanza una comprensión de la excepción que ésta no realiza. La racionalidad técnica es una racionalidad generalizante y calculadora. ${ }^{30}$ Se trata allí de establecer vínculos entre tipos de fenómenos sensoperceptibles. Lo que se persigue con este modo de operar es volver a la realidad, así comprendida, calculable y previsible. Para conseguir el incremento en las posibilidades de cálculo, y luego en las de control y de disposición, la racionalidad técnica margina de su campo lo excepcional: lo inusitado, lo no-objetivable, lo incuantificable, lo que escapa a las regularidades y constancias, lo misterioso, lo trascendente. Lo excepcional no pasa por el criterio de "calculabilidad". La excepción no se deja controlar ni comprender según el nuevo "método de la contemplación de la naturaleza". 31 Ella no se halla a la mano, ni es reconducible a una extensión calculable y disponible. Lo excepcional queda de antemano excluido en este tipo de racionalidad. ${ }^{32}$

La racionalidad técnica restringe lo excepcional, lo margina de su campo de comprensión, pero esta labor sólo puede realizarla en la medida en que supone previamente a aquella misma excepción. La prescindencia oculta un condicionamiento previo. La racionalidad técnica es un aspecto de una existencia que emerge desde un abismo sobre el cual se halla suspendida. Para Schmitt la existencia humana es efectivamente "indeterminada, insondable". 33 El ser humano emerge en la existencia simplemente, pero sin poder dar cuenta de ese hecho. Ninguno de los conocimientos que obtiene de los objetos mundanos, acotados, cosificados, le sirve para llegar a comprender su existencia. Existir es, en cierta forma, no poder dar cuenta del hecho de existir, quedar remitidos irrevocablemente a un abismo. ${ }^{34}$ La existencia es excepción, pues no resulta comprensible al modo en el que comprendemos objetos. Es una "nada" o abismo: una "nada" de "algo," que no se halla determinada, como sí está determinado todo "algo".35 Es una indeterminación, un "ilimitado,"36 un "inconceptualizable,"37 un "infinito,"38 desde el cual recién nos volvemos posibles. 39

Schmitt detecta, tempranamente, 40 que el esfuerzo que se lleva adelante en la racionalidad científico-técnica, mediante el cual el mundo es reducido a cuerpo neutral, calculable

30 Cf. C. Schmitt. Theodor Daublers “Nordlicht”. Berlín: Duncker \& Humblot, 1991, 60.

31 C. Schmitt. Op. cit., 15.

32 Cf. C. Schmitt. Op. cit., 56-57, 60, 63; Römischer Katholizismus und politische Form. Stuttgart: Klett-Cotta, 1984, 26.

33 C. Schmitt. Der Begriff des Politischen, 60.

34 Cf. C. Schmitt. Glossarium, 60, 94, 212; Der Begriff des Politischen, 60.

35 C. Schmitt. Glossarium, 212. "El ser humano no está en el 'aquí y ahora,' sino que 'tras' él, tras de sí, sin lugar, en la nada [...] su existencia es, en verdad, emplazada en la nada". H. Plessner, Dei Stufen des Organischen und der Mensch. Berlín: De Gruyter, 1975, 292.

36 C. Schmitt. Glossarium, 60.

37 C. Schmitt. Op. cit., 212.

38 C. Schmitt. Op. cit., 94.

39 Cf. H. Plessner. Op. cit., 288-292.

40 Antes todavía que Heidegger; cf. M. Heidegger, por ejemplo, Logik. Die Frage nach der Wahrheit. 
y manipulable, no es, a su vez, puramente neutral. ${ }^{41}$ El ethos de la neutralidad valorativa con el que opera el científico moderno es sólo aparente. La racionalidad científico-técnica se guía por un interés, persigue un fin, no obstante que no se pregunta por él. Se trata de incrementar las posibilidades de cálculo, previsión y control, a la vez que de evitar lo imprevisible, lo incalculable, lo misterioso, lo incontrolable, la excepción. Por eso, precisamente, la ciencia simplifica la realidad originaria, pues sólo de ese modo logra volverla calculable y, mediante la técnica, controlable. ${ }^{42}$ Ese afán de control expresa una motivación que posee dos aspectos. En el Glossarium anota Schmitt: "causalidad=calculabilidad=voluntad de poder".43 Mediante la racionalidad reduccionista de cuerpos determinados, la ciencia moderna logra la calculabilidad de la naturaleza. Esta intención o interés de cálculo pretende satisfacer aquella voluntad de poder. En el mismo Glossarium, Schmitt plantea, empero, que el afán de control tras la racionalidad científico-técnica se dirige a superar la "angustia" (Angst) ante lo incierto. ${ }^{44}$ Angustia y voluntad de poder serían como dos caras de una misma moneda. La voluntad de control emerge como intento de paliar la angustia ante la incertidumbre y esa angustia surge, de su lado, ante la constatación de la imposibilidad de someter la existencia a la voluntad de control. El esfuerzo de control de la realidad como expresión de angustia y voluntad de poder se realiza mediante la "Utopía", la cual es definida por Schmitt como "organización para la superación de la angustia".45 Allí se expresa la voluntad de poder como esfuerzo por dejar atrás la incertidumbre y la angustia que ella genera. El intento utópico de racionalización o control de la existencia se halla, sin embargo, condenado al fracaso, pues la "excepción", 46 las "infinitas posibilidades", 47 la "posibilidad de lo infinito"48 son insoslayables. "Lo último y lo decisivo no puede ser "fabricado",.49

Gesamtausgabe. Frankfurt a.M.: Klostermann, 1975 ss.,, vol. 21, 144, 156-158; Sein und Zeit. Tübingen: Niemeyer, 2001, 69. Villacañas muestra que varios de los motivos fundamentales de la crítica heideggeriana de la técnica ya se encontraban en escritos tempranos de Schmitt; cf. J. L. Villacañas. "La edad de la técnica: Reflexiones sobre Heidegger, Jünger y Schmitt". Poder y conflicto. Ensayos sobre Carl Schmitt. Madrid: Editorial Biblioteca Nueva, 2008, 79-110.

${ }^{41}$ Cf. C. Schmitt. Theodor Däublers "Nordlicht", 59-60, 66-67; Politische Theologie, 20-21, 40, 46; Glossarium, 195; Der Nomos der Erde, 6. John P. McCormick expone con detalle la relación de las críticas de Schmitt y Georg Lukács a la racionalidad científico-técnica, con el pensamiento de Max Weber; cf. J. P. McCormick. Op. cit., 31-82. La crítica de Schmitt (ya formulada en el año 1916) es, empero, previa a la de Lukács, cuya obra Geschichte und Klassenbewusstsein es del año 1923.

42 Cf. J. Habermas. Ciencia y técnica como "ideología". Madrid: Tecnos, 1992, 170; H. E. Herrera. Más allá del cientificismo. Santiago de Chile: Ediciones UDP, 2011, 63-65.

43 C. Schmitt. Glossarium, 34 (nota a pie de página).

44 C. Schmitt. Op. cit., 36, 39, 93-95. Con su alusión a la voluntad de poder y al pretender develar la racionalidad científico-técnica como expresión de la angustia humana frente a lo misterioso de la existencia, Schmitt se está colocando en la tradición de Friedrich Nietzsche; cf. F. Nietzsche. GötzenDämmerung. Kritische Studienausgabe. Berlín: De Gruyter, 1999, vol. VI, 93; Die fröhliche Wissenschaft. Kritische Studienausgabe, vol. III, 593-594.

45 C. Schmitt. Glossarium, 94-95.

46 C. Schmitt. Politische Theologie, 20-21.

47 C. Schmitt. Glossarium, 94.

48 C. Schmitt. Ibid. Cf. C. Schmitt. Politische Theologie, 21.

49 C. Schmitt. Theodor Däublers "Nordlicht", 56. 
La comprensión jurídica de la existencia asumida por Schmitt se distingue de la comprensión técnica porque en ella hay una apertura a la excepción de la cual la existencia humana emerge y sobre la cual se asienta. Esta excepción existencial no es sólo ni preponderantemente la excepción política, sino ante todo: lo indeterminado, 50 la muerte, 51 lo infinito, 52 la trascendencia, 53 aquello que nos resulta imprevisible, "que ningún cerebro humano ha concebido," 54 frente a lo cual experimentamos inseguridad y angustia. ${ }^{55}$ La excepción política aparece aquí sólo como un caso de esa excepción más amplia. Eventualmente la excepción política puede ser controlada, mediante dispositivos como el estado de excepción y otros artilugios técnicos. Pero Schmitt no cree ni en la eficacia completa de esos mecanismos para superar la excepción política, ni tampoco en que baste superar la excepción política para cancelar la posibilidad de la excepción en general.

Una crisis política grave, una guerra, por ejemplo, es una excepción que pone en riesgo el orden jurídico y puede llegar a alterar la situación de tal suerte que la normalidad estalle y dé paso a una situación política muy diversa. Sin embargo, la excepción política es relativa, en tanto que no significa la alteración completa de la inmanencia, sino de un aspecto de ella. Es cierto que la excepción política nos enfrenta a la posibilidad de la muerte y en este sentido nos abre a la posibilidad de la excepción radical. Ambas excepciones se encuentran vinculadas, si se repara en la tesis aristotélica de que el ser humano existe propiamente en la pólis, de tal suerte que la crisis de ésta siempre es también la crisis propia y la eventualidad de la propia muerte. Sin embargo, mientras vivimos, el desorden y el cambio político no nos remontan o expelen hacia la nada o hacia algo así como una dimensión nueva en el sentido absoluto del término. En la excepción radical, en cambio, no sólo se alteran condiciones establecidas por el ser humano: la "ley positiva". Aquí adviene, en cambio, lo radicalmente nuevo, lo que no es admisible dentro del marco de las condiciones previas de la existencia.

Atendido a que Schmitt admite la excepción radical en su pensamiento, no parece completamente correcto afirmar que la doctrina schmittiana del estado de excepción esté motivada por un ferviente esfuerzo de clausurar la excepción, sea como excepción política, sea como advenimiento de lo radicalmente nuevo. $56 \mathrm{Al}$ contrario, como he mencionado, en Teología política la excepción es especialmente valorada. Allí repara Schmitt en que la excepción es "más interesante que la regla [...]. En la excepción el poder de la vida real

\footnotetext{
50 Cf. C. Schmitt. Glossarium, 36, 264.

51 Cf. C. Schmitt. Op. cit., 39, 93-94.

52 Cf. C. Schmitt. Op. cit., 94-95.

53 Cf. C. Schmitt. Op. cit., 37, 60; M. Rissing y Th. Rissing. Politische Theologie. Schmitt-DerridaMetz. Munich: Wilhelm Fink, 2009, 56.

54 C. Schmitt. Hamlet oder Hekuba. Der Einbruch der Zeit in das Spiel. Stuttgart: Klett-Cotta, 1985, 47.

55 Cf. C. Schmitt. Glossarium, 39, 93, 94.

56 La comprensión schmittiana de la excepción permite matizar las observaciones de Jacques Derrida y de Thilo y Michaela Rissing, respecto a que el pensamiento de Schmitt se hallaría motivado por la angustia ante lo nuevo y excepcional; cf. J. Derrida. Políticas de la amistad. Madrid: Trotta, 1998, 87, 107-108; M. Rissing y Th. Rissing. Op. cit., 108-109.
} 
irrumpe a través de la corteza de una mecánica paralizada en la repetición". ${ }^{57}$ Además, para Schmitt, sólo un utopista podría pensar en la suficiencia de los dispositivos técnicos para controlar las "posibilidades infinitas del ser humano," el carácter indeterminado e insondable de la existencia.

En este sentido, cabría preguntarse, volviendo a la interpretación que Agamben hace de la teoría schmittiana del estado de excepción, si acaso la clara consciencia que tiene Schmitt respecto de la excepción como carácter constitutivo de nuestra existencia, no puede ser precisamente un criterio que muestre la relatividad de los intentos técnico-jurídico-políticos por bloquear la excepción radical e integrar la excepción política en el derecho. Schmitt sabe de esta relatividad,58 no obstante que no renuncia a una doctrina del estado de excepción. La apertura de la comprensión jurídica a la excepción, en el sentido más amplio que le da Schmitt a la expresión, es decir: no sólo a la excepción política, sino a la excepción radical que es la existencia humana, puede operar aquí como la base de una crítica schmittiana de la doctrina del estado de excepción del propio Schmitt. La consciencia sobre la ineficacia final de cualquier esfuerzo de dominación soberana, puede volverse el principio de una política de la desvinculación de la atadura de la vida concreta por parte de la violencia estatal y en la cual se abra un espacio para la crítica política de la estatalidad. 59

\section{La oposición entre nuda vida y meras normas}

Pese a que Schmitt es consciente de la incapacidad de la técnica para suprimir la excepción, lo mismo que de los riesgos de manipulación y control que produce la racionalidad técnica, sin embargo, sigue afirmando su doctrina del estado de excepción. La actitud de Schmitt no sería de mera porfía. En sus textos hay un argumento para sostener que la declaración del estado de excepción no es necesariamente y en todos los casos mera manipulación. A diferencia de la oposición que establece Agamben entre nuda vida y norma pura, la cual sólo puede ser mediada por la violencia soberana, para Schmitt antes de la intervención soberana la vida misma se halla ordenada jurídicamente. De esta manera se vuelve posible una declaración del estado de excepción dirigida a restablecer el orden.

Agamben opone la nuda vida como hecho al derecho como norma. Antes de la determinación de los individuos por parte de la decisión soberana éstos carecen de significado jurídico. 60 Previo a la intervención soberana, los individuos serían pura vitalidad, su existencia sería entonces lo radicalmente heterogéneo con los conceptos jurídicos normales. Entre "la vida y la norma, no hay ninguna articulación substancial". ${ }^{61}$ Recién mediante esa intervención se forzaría a la realidad de la vida desnuda, sometiéndosela a la juridicidad. En

57 C. Schmitt. Politische Theologie, 21.

58 Cf. C. Schmitt. Theodor Däublers "Nordlicht", 56-57, 59-60, 63; Politische Theologie, 20-21; Römischer Katholizismus, 26; Der Begriff des Politischen, 60; Glossarium, 34 (nota al pie), 36, 39, 53, 82, 93-95; Politische Theologie II, 97-98.

59 Cf. G. Agamben. Estado de excepción, 125-128.

${ }^{60} \mathrm{Cf}$. G. Agamben. Homo sacer, 142. Sería posible pensar en una nuda vida previa al lenguaje, la cual recién mediante la política es puesta en relación con el "logos"; op. cit., 17-18.

${ }^{61}$ G. Agamben. Estado de excepción, 126. 
la comprensión de Schmitt, en cambio, ya antes de la intervención soberana, la existencia humana se halla ordenada jurídicamente.

A este orden como normatividad realizada, apunta, precisamente, Schmitt en su comprensión del nomos. Agamben opone "nomos y physis", 62 los cuales, en cambio, Schmitt se preocupa de no separar: "la destrucción del significado originario [de nomos] es realizada por una serie de distinciones y antítesis. Entre ellas la más importante es la oposición de nomos y physis". 63 A pesar de que conoce El nomos de la tierra y que repara en que allí Schmitt vincula originariamente "nomos" con la "toma de la tierra" y con una unidad de "orden y situamiento", 64 Agamben deja de lado los aspectos cualitativos del nomos, y lo reduce a una toma de tierra como acto soberano que es ante todo una decisión sobre la excepción. ${ }^{65}$ La comprensión schmittiana del nomos, en cambio, apunta a un orden cualitativo, que emerge a partir de la relación que establece el ser humano con la tierra. "Nomos es la medida de repartición y localización del fundamento y suelo de la tierra en un determinado orden". 66 Schmitt alude antes a la medida o al criterio, que a una mera decisión soberana. El nomos es una medida que emana del acto de toma de la tierra. La tierra, en sí misma, contiene medidas de orden. Al inicio de la obra, Schmitt señala que la tierra guarda en ella un orden o medida jurídicos. Hay un "orden de sentido de la tierra (Sinnreich der Erde)". ${ }^{67}$ De tres maneras, contiene la tierra una medida jurídica o un orden de sentido:

Primero, la tierra contiene en ella misma [...] una medida interior. Pues el esfuerzo y el trabajo, siembra y cultivo que realiza el ser humano sobre la tierra fecunda, es recompensado de manera justa por la tierra mediante el crecimiento y la cosecha. [...] Segundo, el suelo despejado y labrado por los hombres exhibe líneas firmes, en las cuales se vuelven posibles divisiones determinadas. [...] Tercero, finalmente, la tierra porta sobre su suelo firme cercados y vallas, mojones fronterizos, muros, casas y otras edificaciones. Aquí se vuelven manifiestos los órdenes y localizaciones de la vida humana en común. 68

El nomos no es simple y fundamentalmente un acto soberano de determinación, sino que se halla remitido a una medida previa, de justicia, límites y fundamento. Por eso, a saber, porque el nomos es antes medida que decisión soberana, Schmitt rechaza la identificación del nomos con una "mera norma y posición", con "estatutos y posiciones", con la "posición legal", lo mismo que la "oposición entre nomos y physis", 69 en todas las cuales el nomos pierde su referencia a esa medida previa de justicia, límites y fundamento y pasa a ser entendido como una posición normativa meramente arbitraria.

62 G. Agamben. Homo sacer, 42.

63 C. Schmitt. Der Nomos der Erde, 38.

64 G. Agamben. Homo sacer, 32.

65 Cf. G. Agamben. Ibid.

66 Cf. C. Schmitt. Der Nomos der Erde, 40. Villacañas sugiere que en Schmitt la "desnuda violencia" puede desencadenarse precisamente por "la falta de Nomos". J. L. Villacañas. "En diálogo con Weber. Sobre La tiranía de los valores de Carl Schmitt”. H. E. Herrera (ed.). Carl Schmitt. Análisis Crítico. Revista de Ciencias Sociales (número especial). Valparaíso: Edeval, 2012, 99.

67 C. Schmitt. Der Nomos der Erde, 6.

68 C. Schmitt. Op. cit., 13.

69 C. Schmitt. Op. cit., 38. 
El orden, plantea Schmitt, es condición de validez de las normas. 70 "No hay norma alguna que sea aplicable sobre un caos". ${ }^{71} \mathrm{El}$ caos al que usualmente se refiere Schmitt es el caos político, la situación de guerra interna o desorden social profundo, controlable - eventualmente- mediante la intervención soberana capaz de normalizar la excepción. Sin embargo, el caos también puede extenderse más allá de la situación de indeterminación política. En Schmitt la excepción o el caos nunca es completamente acotable desde la inmanencia. ${ }^{72}$ Ahora bien, caos puede significar la supresión de la conformación típica de la existencia, de nuestro mundo cotidiano, así como a la pérdida de la orientación teleológica de las situaciones en las que originariamente nos encontramos. Puede así pensarse en un mundo completamente caótico, desencajado, radicalmente excepcional, en una abigarrada y caleidoscópica sucesión en la cual todo cambia, sin punto de referencia, sin estructuraciones típicas. ${ }^{73}$ También es posible representarse una existencia que, en todos sus aspectos, se volviese completa y persistentemente indiferente, neutral, carente de sentido. ${ }^{74}$ En medio de un mundo así no sería posible ni la tipicidad ni un sentido de las acciones. Allí, en consecuencia, la aplicación, incluso la aplicación violenta, de normas a casos sería inviable. Tanto la falta de tipicidad, cuanto la falta de motivos para las acciones impedirían una tal intervención jurídica soberana. En Teología política Schmitt aclara que, en el caos político, no obstante que hay desorden, éste se halla acotado: "el estado de excepción es siempre algo todavía distinto de una anarquía y un caos". En la medida en que aún allí hay un cierto "orden", "el estado de excepción es accesible también al conocimiento jurídico",75 algo que en un caos completo, en la ausencia total de orden y sentido, resultaría imposible.

La afirmación de una estructuración "jurídica" de la existencia (con un cierto orden y sentido), previa a la intervención soberana, no sólo se deja justificar a partir de los textos de Schmitt. Además, se puede mostrar que ella es condición de la elucidación de la distinción que hace el propio Agamben, entre una intervención soberana reactiva a una excepción previa y una intervención soberana que declara el estado de excepción para provocar activamente la excepción. Agamben plantea que la distinción entre la preponderancia de uno u otro "uso" del estado de excepción está marcada cronológicamente por la Primera Guerra Mundial, donde el segundo uso predominó. ${ }^{76}$ Entonces, cuando la "excepción se convierte en regla, el espacio de la nuda vida que estaba situada originariamente en al margen del orden jurídico, va coincidiendo de manera progresiva con el espacio político". ${ }^{77}$ Esta distinción plantea luego la pregunta acerca de cómo distinguir entre un uso reactivo y uno activo del estado de excepción. Sólo bajo el supuesto de una relación previa entre norma y vida, sólo bajo el supuesto de un orden anterior que se rompe, descompensa o entra en crisis, tiene

\footnotetext{
70 Cf. C. Schmitt. Über die drei Arten des rechtswissenschaftlichen Denkens. Berlín: Duncker \& Humblot, 1993, 19-20.

71 C. Schmitt. Politische Theologie, 19.

72 Cf. C. Schmitt. Politische Theologie, 20-21; Hamlet oder Hekuba, 47.

73 Cf. C. Schmitt. Über die drei Arten des rechtswissenschaftlichen Denkens, 20.

${ }^{74}$ Cf. C. Schmitt. Der Wert des Staates und die Bedeutung des Einzelnen. Berlín: Duncker \& Humblot, 2004, 36.

75 C. Schmitt. Politische Theologie, 18-19.

76 Cf. G. Agamben. Homo sacer, 22, 74; Estado de excepción, 11, 17, 125-127.

77 G. Agamben. Homo sacer, 19 (subrayados míos).
} 
sentido hablar de un uso reactivo distinto a una mera producción espontánea de la excepción mediante la declaración del estado de excepción.

En la medida en que esta normalidad o estructuración jurídico-política es previa a la intervención soberana, puede decirse que aquí nos hallamos en un caso de normalidad "a priori" o anterior a la racionalidad técnica. En el pensamiento de Schmitt habría así base para sostener una racionalidad específicamente jurídica como diversa de una racionalidad estrictamente técnica. El estado de excepción activo sería parte de una racionalidad técnica, que se caracteriza por su inclinación hacia el polo espontáneo y a someter a control la realidad sin atender a ninguna medida o criterio que pueda interponerse a ese afán de control. En cambio, el reconocimiento de una medida de orden previa a la acción humana, de una medida que se despliega a partir de la toma de la tierra, pero que se halla de antemano, permite pensar en un estado de excepción como respuesta a la crisis del orden y el intento de instaurar un nuevo orden, que, sin embargo, no sea una mera posición desarraigada, sino que pueda adecuarse a la medida previa contenida en la realidad.

\section{5. ¿Vida como "nuda vida"?}

Probablemente la fuente de la diferencia entre Schmitt y Agamben haya que encontrarla en el concepto de "nuda vida" con el cual opera este último. Agamben rastrea el origen de este concepto en el griego "zó̀ "’, y que contrapone al griego "bios", el cual alude a la forma o modo de vida propio de un individuo o grupo. ${ }^{78} \mathrm{La}$ "nuda vida" apunta al "simple hecho de vivir", 79 al "mero cuerpo viviente", 80 separado de toda otra determinación normativa o cultural. ${ }^{81}$ Esta noción resulta difícilmente compatible con la idea schmittiana de un orden o medida jurídicos en la existencia humana, como condición necesaria de la aplicación de normas a casos. Además, soslaya un aspecto requerido, para Schmitt, por la comprensión humana en general.

Jacques Derrida ha cuestionado la distinción desde la cual Agamben obtiene la noción de "nuda vida". De un lado, en las fuentes, por ejemplo, en Aristóteles, se usa la expresión $z \bar{o} \bar{e}$ para referirse tanto a la vida plena de Dios, cuanto para describir el modo de vida político. ${ }^{82} Z \bar{o} \bar{e}$ sería allí una vida dotada ya de una cierta medida interna. De otro lado, la noción de "nuda vida" no parece ser intrínsecamente distinta e independiente. Derrida cita la afirmación de Heidegger: "Para el obstinado (Eigenssinige) la vida es sólo vida". ${ }^{83}$ En cambio, Heidegger entiende que la existencia humana se caracteriza por su apertura comprensiva. Sin esa apertura comprensiva no hay propiamente existencia humana. La introducción de una separación, en la existencia humana, entre vida biológica y la capacidad de comprender,

\footnotetext{
78 G. Agamben. Homo sacer, 9.

79 G. Agamben. Ibid.

80 G. Agamben. Op. cit., 12.

81 Cf. G. Agamben. Op. cit., 17-18.

82 Cf. J. Derrida. The Beast and the Sovereign. Chicago: The University of Chicago Press, 2011, 316,

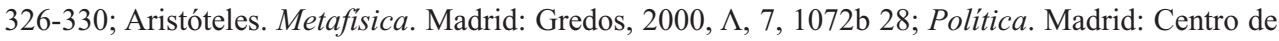
Estudios Constitucionales, 2005, I, 2, 1253a 4.

83 M. Heidegger. Einführung in die Metaphysik. Tübingen: Niemeyer, 1998, 100; cf. J. Derrida. Op. cit., 306.
} 
entre sola corporalidad y lenguaje, no parece posible. ${ }^{84}$ Una nuda biología originalmente separada de la comprensión no sería humana. De hecho, la idea de una nuda vida parece ser el resultado de un modo determinado de comprensión, en el cual la existencia originaria es dividida, separada, escindida en aspectos que, sin embargo, originariamente se encuentran unidos.

La apertura comprensiva, tanto en los textos de Heidegger como en los de Schmitt, admite diversos modos. ${ }^{85}$ Uno de esos modos es el desocultamiento que realiza la técnica. ${ }^{86}$ La técnica, en este sentido, es, antes que la simple máquina o lo maquinal, un modo de comprensión, y en esto coincide Heidegger con lo que Schmitt plantea en El concepto de lo político. Si para Heidegger la "técnica" originariamente "no es [...] algo maquinal", sino "la manera en la cual lo real se descubre como existencias", 87 para Schmitt la técnica no se refiere primariamente a la "mecánica sin alma", sino que ella emana de lo que él denomina el "espíritu de la tecnicidad", 88 esto es, el modo de comprensión que está en la base de la técnica como mecánica. 89

La determinación de algo así como la vida estrictamente biológica, puede ser entendida como el resultado de la aplicación sobre la existencia humana del modo de comprensión específicamente técnico. Es recién entonces que puede conseguirse separar de esa existencia sus aspectos de sentido o prácticos y sus remisiones a una trascendencia comprensiva y obtenerse algo así como un objeto puramente neutral: la nuda vida corporal. Agamben de hecho afirma que el nudo cuerpo, la "vida biológica", emerge en la modernidad como el correlato de la "tecnología". 90 Heidegger indica, en un mismo sentido, que la técnica como "modo del desocultar" devela al ente de tal manera que emerge como disponible, como "existencias" disponibles. 91 "La naturaleza" es aquí representada como "un conjunto calculable de relaciones de fuerzas". 92

Pero la comprensión técnica descansa sobre supuestos que están más allá de los límites de una existencia puramente biológica. En la medida en que la comprensión técnica hace foco sobre los aspectos meramente biológicos, soslaya los supuestos sobre los que ella reposa como modo de comprensión. En este sentido, tomar al resultado de la aplicación sobre la existencia de un modo de comprensión técnica como la existencia originaria importa, cual indica Heidegger, cerrarse el paso "hacia un desocultamiento más originario". 93 Superar la

${ }^{84}$ Cf. G. Agamben. Homo sacer, 17-18.

85 Junto al de la técnica, se halla en Heidegger, por ejemplo, el del arte; M. Heidegger. Der Ursprung des Kunstwerks. Stuttgart: Reclam, 1960, 29, 74. En Schmitt, además de la comprensión técnica, es posible identificar un modo de comprensión jurídico de la existencia, como se evidencia en El nomos de la tierra o en Sobre los tres modos de pensar la ciencia jurídica. Sobre los alcances de este modo de comprensión, cf. C. Schmitt. "Die Lage der europäischenRechtswissenschaft", 427.

86 M. Heidegger. "Die Frage nach der Technik". Vorträge und Aufsätze. Stuttgart: Klett-Cotta, 2000, 16.

${ }^{87}$ M. Heidegger. Op. cit., 27.

88 C. Schmitt, Der Begriff des Politischen, 92, 93.

89 McCormick, quien destaca esta relación entre Heidegger y Schmitt, indica que en ambos casos se trataría de algo así como una "fuerza conductora detrás del surgimiento y funcionamiento continuo de las máquinas básicamente carentes de vida de la tecnología moderna"; J. P. McCormick. Op. cit., 45.

90 G. Agamben. Homo sacer, 12.

91 M. Heidegger. "Die Frage nach der Technik", 30.

92 M. Heideger. Ibid.

93 M. Heidegger. Op. cit., 32. 
obstinación de tomar al resultado de la comprensión técnica por la existencia originaria, exige atender a esos supuestos.

En cada acto comprensivo el ser humano se halla más allá de la inmanencia. Schmitt adhiere a la determinación del ser humano que hace Helmut Plessner como "un ser primariamente capaz de crear distancia". 94 Esa capacidad de crear distancia es requerida por la comprensión. Sólo desde un distanciamiento respecto de sí mismo, puede el "yo" "volver completamente sobre sí mismo" en la reflexión y comprenderse. ${ }^{95}$ El distanciamiento es condición de toda comprensión, de la que tiene el ser humano tanto respecto de mí mismo, cuanto de los otros. Dicho distanciamiento supone, de su lado, el emplazamiento del yo en una cierta indeterminación, en una excepcionalidad o trascendencia, en una instancia diversa a la de los entes acotados por medio de la comprensión técnica. Sólo así puede el ser humano comprender cualquier ente particular y comprender también la dimensión óntica en general, incluido su aspecto óntico, a saber, saliéndose de las determinaciones a las que los entes están sometidos. ${ }^{96}$ En cambio, la "inmanencia pura", la "identidad pura", 97 significa, como señala Schmitt, en definitiva, la "eliminación de toda distancia (Abstand)", incluso de la "inteligencia."98 Heidegger indica, en un sentido similar al de Plessner y Schmitt:

El Dasein se encuentra de antemano allende el ente en general. A este estar-allende el ente lo llamamos la trascendencia. Si el Dasein no trascendiera en el fundamento de su ser [...], entonces no podría comportarse jamás respecto de su ente, o sea, tampoco respecto de sí mismo. ${ }^{99}$

La existencia humana queda originariamente remitida, para Schmitt y Heidegger, a una trascendencia como condición sólo bajo la cual puede tener lugar la comprensión. La noción de nuda vida aparece como una abstracción que deja de lado este aspecto de la existencia. Así, no es sólo que esa noción soslaye la idea schmittiana de un orden y medida prácticos en la existencia, requeridos por la aplicación de normas a casos, sino que además, la misma comprensión técnica, en la cual puede emerger algo así como una nuda vida, supone un requisito que es, por principio, incompatible con esta noción. 100

\author{
Hugo Eduardo Herrera \\ Instituto de Humanidades \\ Universidad Diego Portales (Chile) \\ hugoeduardoherrera@gmail.com
}

\footnotetext{
94 C. Schmitt. Der Begriff des Politischen, 60.

95 H. Plessner. Op. cit., 292.

96 Cf. H. Plessner. Ibid.

97 C. Schmitt. Glossarium, 84.

98 C. Schmitt. Ibid.

99 M. Heidegger. Was ist Metaphysik? Gesamtausgabe, vol. 9, 115.

100 El problema de la aplicación de reglas a casos también apunta, en último término, a la posibilidad de la comprensión. Casos radicalmente a-típicos o una situación completamente desprovista de sentido, harían inaplicables las reglas porque se volverían en su a-tipicidad o carencia de sentido en casos incomprensibles.
} 